\title{
Article \\ Method for Controlling Edge Wave Defects of Parts during Roll Forming of High-Strength Steel
}

\author{
Ce Liang ${ }^{1} \mathbb{D}$, Sinan $\mathrm{Li}^{1}$, Jicai Liang ${ }^{1,2, *}$ and Jiandong $\mathrm{Li}^{1,2}$ \\ 1 Key Laboratory of Automobile Materials, Ministry of Education, College of Materials Science and \\ Engineering, Jilin University, Changchun 130025, China; liangce@jlu.edu.cn (C.L.); \\ lisn20@mails.jlu.edu.cn (S.L.); henrylee@jlu.edu.cn (J.L.) \\ 2 Chongqing Research Institute, Jilin University, Chongqing 401123, China \\ * Correspondence: liangjicai@126.com
}

check for updates

Citation: Liang, C.; Li, S.; Liang, J.; Li, J. Method for Controlling Edge Wave Defects of Parts during Roll Forming of High-Strength Steel. Metals 2022, 12, 53. https://doi.org/10.3390/ met12010053

Academic Editor: José

Valdemar Fernandes

Received: 22 October 2021

Accepted: 20 December 2021

Published: 27 December 2021

Publisher's Note: MDPI stays neutral with regard to jurisdictional claims in published maps and institutional affiliations.

Copyright: (c) 2021 by the authors. Licensee MDPI, Basel, Switzerland. This article is an open access article distributed under the terms and conditions of the Creative Commons Attribution (CC BY) license (https:/ / creativecommons.org/licenses/by/ $4.0 /)$.

\begin{abstract}
Cold roll forming is suitable for sheet metal processing and can provide a new method for the production and processing of anti-collision beams for commercial vehicles. In order to accurately control the edge wave defects of the parts in the roll forming process, we used the professional roll design software COPRA to design the roll pattern and used the professional finite element analysis software ABAQUS to establish a three-dimensional finite element analysis model of the " $\mathrm{b}$ "-shaped cross-section. We analyzed the factors affecting the edge wave by controlling different process parameters (the thickness of the sheet, the height of the flange, and the forming speed), and the best process parameter combination was determined. The results showed that the thickness of the sheet, the height of the flange, and the forming speed all had an effect on the edge wave defects of the " $b$ "-shaped cross-section. The influence of sheet thickness was the greatest, followed by flange height and then forming speed. The final selected parameter combination was a sheet thickness of $3 \mathrm{~mm}$, a flange height of $100 \mathrm{~mm}$, and a forming speed of $150 \mathrm{~mm} / \mathrm{s}$. This work provides a theoretical basis for actual production.
\end{abstract}

Keywords: edge wave; cold roll forming; process parameters; finite element analysis

\section{Introduction}

Roll forming is a processing method in which metal sheets sequentially pass through multiple forming rolls to form the required product geometric cross-section profiles. The roll forming process has many advantages, such as high production efficiency, good forming effect, and conservation of forming materials. The roll forming process can produce high-quality cold-formed steel, shorten the production cycle, and improve the production efficiency. Therefore, this processing method is widely used in many fields, such as auto parts, ships, oil and gas pipelines, the power electronics industry, and machinery manufacturing.

High-strength steel has the advantages of reducing weight and improving safety, and it is widely used in key automobile parts, such as anti-collision beams, door sills, and B-pillars. The roll forming process has an excellent forming effect, especially for the processing of complex sections, which is unmatched by the traditional process. Therefore, the use of roll forming technology in the manufacturing process and the use of high-strength steel as material have become the two main ways to achieve lightweight cars and increase crash safety performance [1]. However, due to factors such as material nonlinearity, geometric nonlinearity, and boundary nonlinearity, the deformation of sheet metal during roll forming is quite complex. One of the main problems is that the product produces edge wave defects, which often leads to undesirable product shapes and affects welding performance. Many researchers have studied computer-aided design or numerical simulation of the roll forming process in order to increase productivity and maintain product accuracy during production $[2,3]$. Cao et al. used COPRA software to analyze the roll forming process of 
the asymmetric " 8 " tube, and the results showed that the defects were mainly caused by uneven force on the top of the section [4]. Paralikas et al. used ANSYS/LSDYNA to study the influence of forming parameters on longitudinal and transverse strain and concluded that the roll spacing plays a leading role in the roll forming process [5-7]. Abeyrathna et al. studied the influence of geometric parameters on longitudinal edge strain through experiments and numerical methods, and found that these strains may affect edge wave defects $[8,9]$.

This paper proposes a new roll forming process-a one-time forming of anti-collision beams for commercial vehicles with a "日"-shaped cross-section-to improve the quality defects in the conventional process, especially the edge wave problem. The main factors that affect the edge wave defects of sheet roll forming are the finite element calculation method, friction coefficient, sheet thickness, flange height, and forming speed. This article conducted research on the latter three aspects.

\section{Material Properties and Edge Waves}

\subsection{Material Properties}

This study used B700L automobile beam steel, and some of its material parameters are shown in Table 1. The mechanical properties of the material were measured by a uniaxial tensile test. The data in Table 1 is the average of the three tests. Figure 1a shows a picture of the tensile testing machine, while Figure $1 \mathrm{~b}$ shows the stress-strain curve of the samples obtained from the test results. The hardening behavior was determined to be isotropic. Since ABAQUS needs the true stress and strain values when entering data, the following calculation formula was used to calculate the required values:

$$
\begin{gathered}
\varepsilon=\ln \left(1+\varepsilon_{0}\right) \\
\sigma=\sigma_{0}\left(1+\varepsilon_{0}\right)
\end{gathered}
$$

where $\varepsilon_{0}$ and $\sigma_{0}$ are nominal strain and stress, respectively.

Table 1. Properties of the elastic stage of the material.

\begin{tabular}{cccccc}
\hline Material & $\begin{array}{c}\text { Modulus of } \\
\text { Elasticity } \\
\mathbf{( G P a )}\end{array}$ & $\begin{array}{c}\text { Mass } \\
\text { Density } \\
\left(\mathbf{g} \cdot \mathbf{c m}^{-3} \mathbf{)}\right.\end{array}$ & $\begin{array}{c}\text { Poisson } \\
\text { Ratio }\end{array}$ & $\begin{array}{c}\text { Yield } \\
\text { Strength } \\
\mathbf{( M P a )}\end{array}$ & $\begin{array}{c}\text { Tensile } \\
\text { Strength } \\
\mathbf{( M P a})\end{array}$ \\
\hline $\begin{array}{c}\text { B700L } \\
\text { automotive } \\
\text { beam steel }\end{array}$ & 216 & 7.85 & 0.22 & 728 & 918 \\
\hline
\end{tabular}
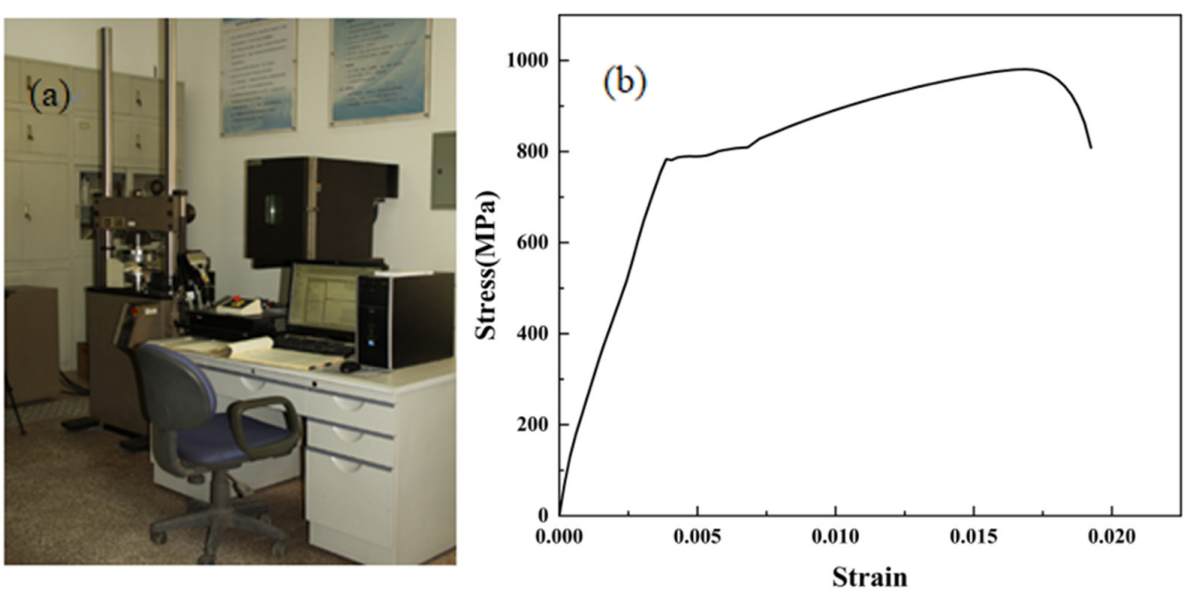

Figure 1. (a) Picture of the tensile testing machine. (b) The stress-strain curve of B700L automotive beam steel. 


\subsection{Causes of Edge Waves and Evaluation Methods}

During the roll forming process, the sheet moves along its forming direction, as shown in Figure 2. Different roll angles will cause different deformations of the sheet in different parts in the forming direction. The edges of the sheet will be elongated due to the increase in height. The space curve $C D$ is longer than the straight line $A B$ in the plane area. Because different parts of the profile have different paths between the two passes, the path length of the side is often greater than the straight-line distance between the two passes. Therefore, the actual formation boundary is inconsistent with the theoretical formation boundary. The outer edge of the sheet is wavy; that is, an edge wave defect is formed. A schematic diagram of an edge wave is shown in Figure 3a. In this paper, the edge wave defects created in the roll forming process were evaluated by the sum of wave heights generated at $100-800 \mathrm{~mm}$ in the sheet forming direction. The schematic diagram is shown in Figure $3 \mathrm{~b}$, and the calculation formula is:

$$
H_{\text {wave }}=\sum_{i=1}^{n} h_{i}
$$

where $H_{\text {wave }}$ represents the total wave height, and $h_{i}$ represents the height of the $i$-th wave. The standard deviation of longitudinal strain $(\Delta \varepsilon)$ was used to measure the influence of each process parameter on the edge wave of the " $b$ " tube, and the calculation formula is:

$$
\Delta \varepsilon=\sqrt{\frac{\sum_{\mathrm{i}=1}^{\mathrm{n}}\left(\varepsilon_{\mathrm{i}}-\bar{\varepsilon}\right)^{2}}{\mathrm{n}}}
$$

where $\mathrm{n}$ is the total number of nodes measured, $\varepsilon_{\mathrm{i}}$ is the longitudinal strain of the $\mathrm{i}$-th node, and $\bar{\varepsilon}$ is the average value of the longitudinal strain of the node.

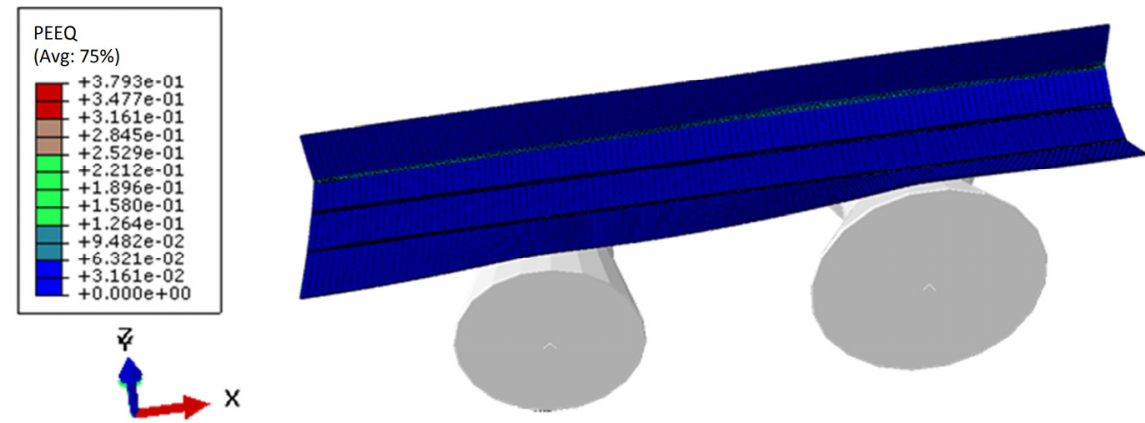

Figure 2. Part of the pass in the roll forming process.
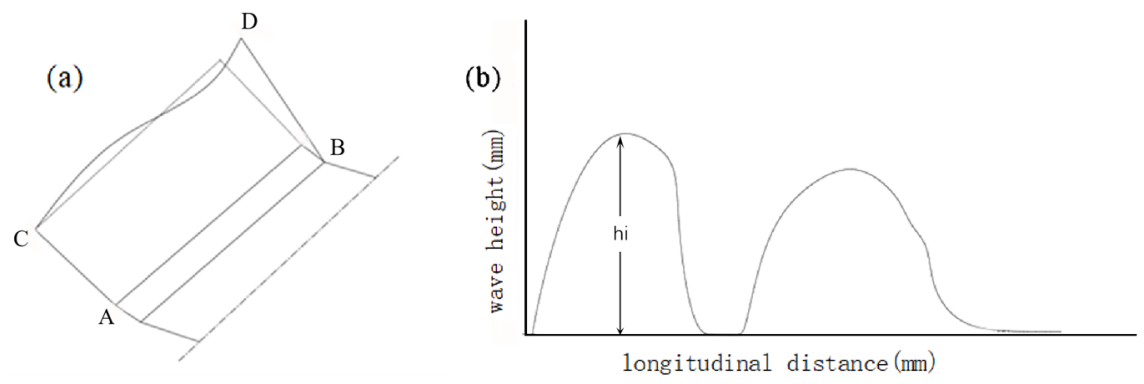

Figure 3. (a) Diagram of an edge wave; (b) The evaluation method of edge waves.

\section{Establishing a " $b$ "-Shaped Cross-Section Finite Element Analysis Model}

\section{1. “日”-Shaped Cross-Section Forming Method}

The section of the anti-collision beam used in commercial vehicles is a "日"-shaped structure. There are two traditional processing methods for "日"-shaped cross-sections. 
The first method is divided into three steps: (1) using roll forming equipment (Shulan General Machinery Co., Ltd., Jilin, China) to process two U-shaped tubes; (2) cutting out a rectangular tube; and (3) welding the two U-shaped steel channels with to rectangular tube, as shown in Figure 4a. The second method is carried out in two steps: (1) using roll forming equipment to process a rectangular tube and a U-shaped tube; and (2) welding the rectangular tube to the U-shaped tube, as shown in Figure $4 \mathrm{~b}$. The welding process in the above two methods is very complicated and requires repeated welding to achieve the forming effect, which not only increases workload, but also results in low production efficiency and poor product quality, and the mechanical properties of the products are difficult to guarantee. In this paper, we adopted a challenging forming method for roll forming the anti-collision beam of commercial vehicles with a "日”-shaped section at one time, as shown in Figure 4c. This method firstly involves roll forming a " $b$ "-shaped section with roll forming equipment, and performing automatic welding on the inner welding seam; then, rolling the " $b$ "-shaped section again to make the vertical side roll into a Ushaped tube to obtain a "日"-shaped section; and finally, welding the outer weld seam to the edge position after forming. This method not only reduces solder joints, improves material utilization, and production efficiency, but also greatly improves the mechanical properties of the product. In order to reduce the influence of edge wave defects in the forming process and save calculation time, this paper only simulated and analyzed the " $\mathrm{b}$ "-shaped section. The product was tested on a self-developed roll forming process production line, as shown in Figure 4d. The specific product is shown in Figure 4e.

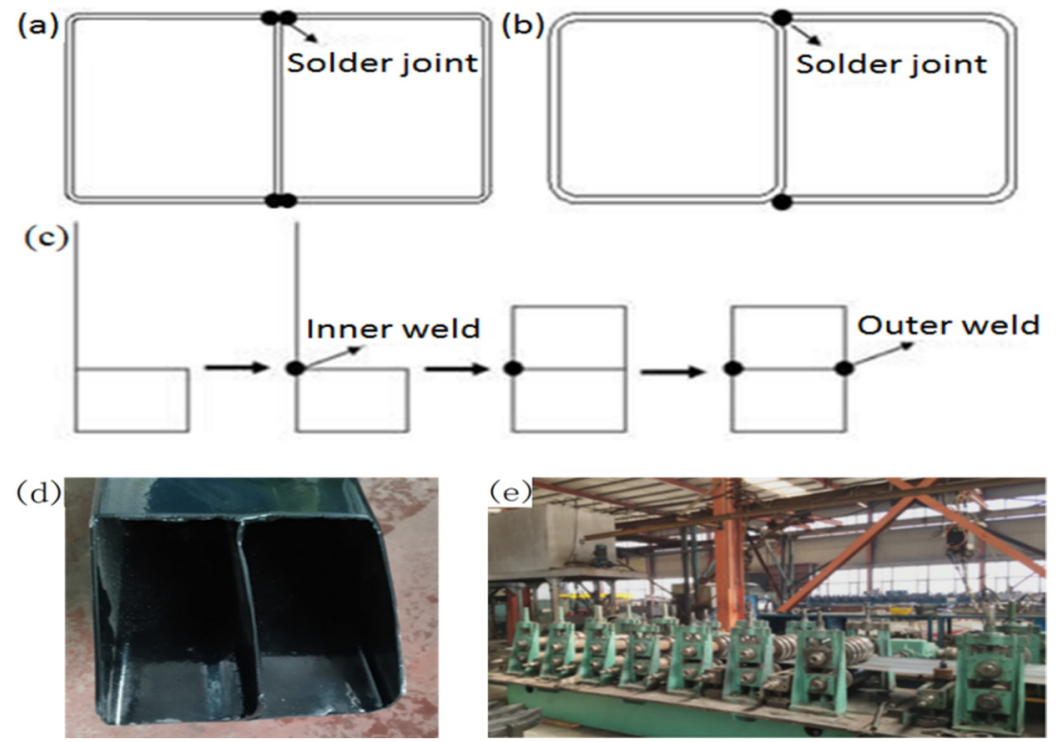

Figure 4. (a) The first method of forming “日”-shaped cross-sections. (b) The second method of forming “日”-shaped cross-sections. (c) One-time roll forming method. (d) Photo of the products. (e) The production line for the roll forming process.

\subsection{Design of the Roll Pattern for the " $b$ "-Shaped Cross-Section}

The roll pattern is a schematic cross-sectional view of the roll forming unit when the sheet is formed. The forming sequence of the " $b$ "-shaped cross-section was designed through the roll pattern design module of COPRA, as shown in Figure 5. The rounding radius was $5.0 \mathrm{~mm}$, the thickness of the sheet was $2.0 \mathrm{~mm}$, and the outside angle was first formed to $75^{\circ}$, with a total of five passes. Then, the two inner corners were formed to $90^{\circ}$, with a total of six passes. Finally, remaining outside corners that were not yet formed were shaped, and each pass was formed at $5^{\circ}$ for a total of 3 passes. With the addition of the guide roll of the first pass, the total number of forming passes was 15 passes. The sheet metal passed through each roll from the first pass, and finally passed through the fifteenth pass to form the required cross-sectional shape. 


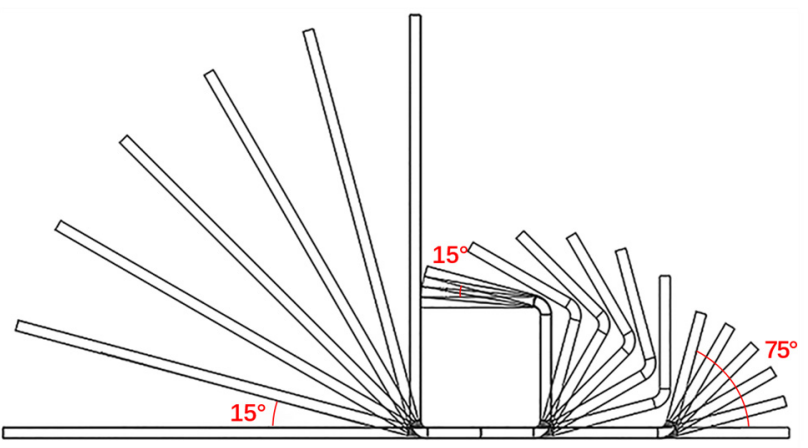

Figure 5. Roll pattern of " $b$ "-shaped cross-section.

\subsection{Optimization of " $b$ "-Shaped Cross-Section Rolls Based on DTM Analysis}

According to the process described above, through the deformation technology module (DTM) of COPRA, the DTM analysis of the pre-designed roll pattern was performed to obtain the strain magnitude of the strip under a given roll pattern design. Figure $6 \mathrm{a}, \mathrm{b}$ show the front view of the designed " $b$ "-shaped cross-section roll pattern DTM analysis and the resulting strain curve with longitudinal distance, respectively. It can be seen from the figure that the strain received by the sheet metal during the forming process is very uneven. As the longitudinal distance increases, the strain increases continuously. This is also in line with the roll forming production process; that is, the sheet metal forming angle is gradually increased to obtain the desired cross-sectional shape of the profile. The strain is controlled below $2.5 \%$, and the maximum and minimum strain difference is controlled at $2 \%$. This indicates that if roll bending molding is carried out in accordance with the designed forming order, the sheet will not be unstable and other behaviors that damage the material structure during the molding process will be absent, indicating that the designed roll pattern can meet the molding requirements.

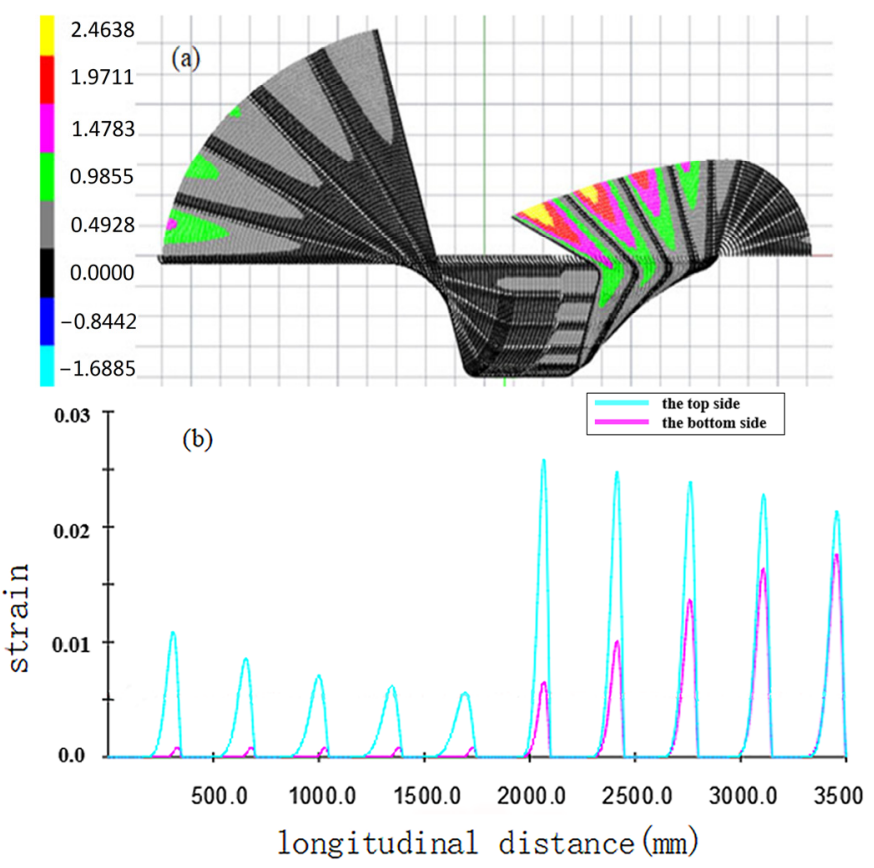

Figure 6. (a) DTM analysis. (b) The changing curve of strain with longitudinal distance.

\subsection{Establish a Finite Element Analysis Model for the " $b$ "-Shaped Cross-Section}

In this paper, the COPRA2021 software from the German company data M company (Valley, Germany) was used to design the roll pattern, and the generated roll pattern diagram was imported into the ABAQUS2017 software from the American company DS 
SIMULIA company (Providence, USA) for roller design. In order to simulate the actual roll forming process, the length of the sheet was set to $900 \mathrm{~mm}$, and the sheet was set as a deformable body. The mesh used C3D8R solid elements [10,11], and the thickness direction was divided into two layers, with a total of 11,340 elements. The roller was set as an analytical rigid body and the roller was angle-relieved [12], the diameter of the upper roller was set to $150 \mathrm{~mm}$, the diameter of the lower roller was set to $100 \mathrm{~mm}$, and the diameter of the vertical roller was set to $100 \mathrm{~mm}$. The pass spacing between the rollers was set to $350 \mathrm{~mm}$. General contact was selected between the roller and the plate, and the friction coefficient was set to 0.2 [13]. The assembly drawing of the " $b$ "-shaped cross-section model is shown in Figure 7. The above simulation conditions and workpiece geometry are shown in Table 2.

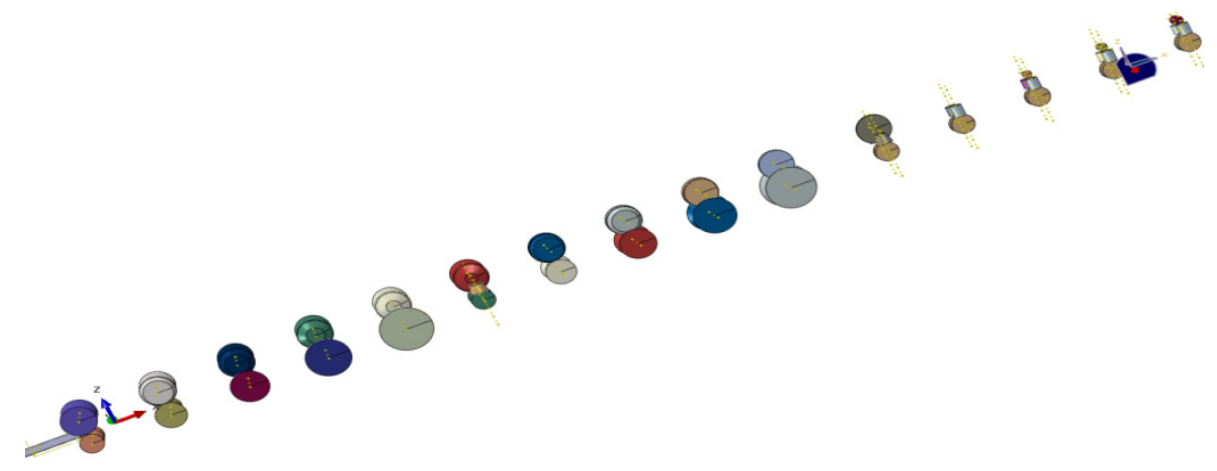

Figure 7. Assembly drawing of " $b$ "-shaped pipe.

Table 2. Simulation and workpiece conditions.

\begin{tabular}{cccc}
\hline \multicolumn{2}{c}{ Roller Conditions } & \multicolumn{2}{c}{ Workpiece Conditions } \\
\hline Total number of models & 15 & Grid vertical size & $3.0 \mathrm{~mm}$ \\
$\begin{array}{c}\text { Center distance of roller } \\
\text { Coulomb friction }\end{array}$ & $350 \mathrm{~mm}$ & Number of elements & 11,430 \\
coefficient & 0.2 & $\begin{array}{c}\text { Number of meshes in the } \\
\text { thickness direction }\end{array}$ & 2 \\
Type of steel body & Analytical rigid body & Mesh type & C3D8R \\
\hline
\end{tabular}

\section{Results and Discussion}

\subsection{Analysis of the Simulation Results for the " $b$ "-Shaped Tube}

It can be seen from the simulation results that the front flange of the pipe tends to shift to the inside. This is due to the complex deformation force of the sheet metal when the rolls are engaged during the roll forming process. Therefore, in order to ensure the accuracy of the simulation results, the stress change at the flange at $100-800 \mathrm{~mm}$ in the length direction of the sheet was selected to be measured. As shown in Figure 8, the stresses at the top, middle, and bottom nodes of the flange are distributed within the longitudinal distance. It can be seen that the stress relationship is greatest at the top of the flange, followed by the middle of the flange, and is lowest at the bottom of the flange. It can also be seen from the figure that the stress and strain curves at the top node of the flange have greater volatility and peak values than the stress and strain curves at the middle and bottom nodes, indicating that the longitudinal stress and strain distribution at the top of the flange is the most uneven, and the longitudinal stress and strain at the bottom of the flange are the same. The strain distribution is the most uniform. Therefore, the top of the flange is most prone to edge wave defects. 

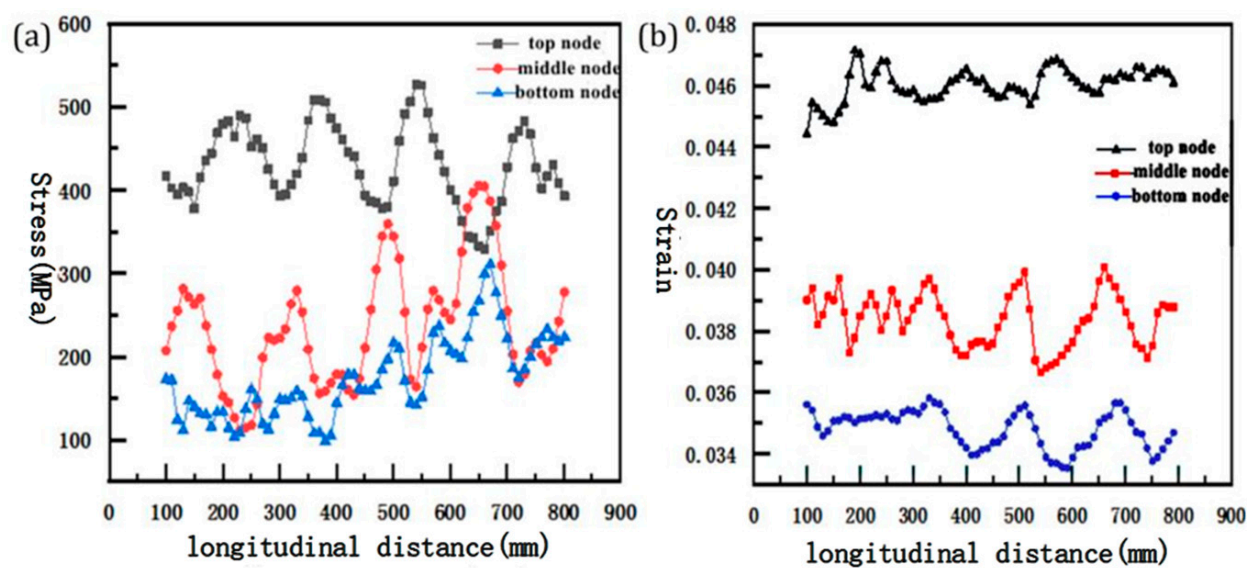

(c)
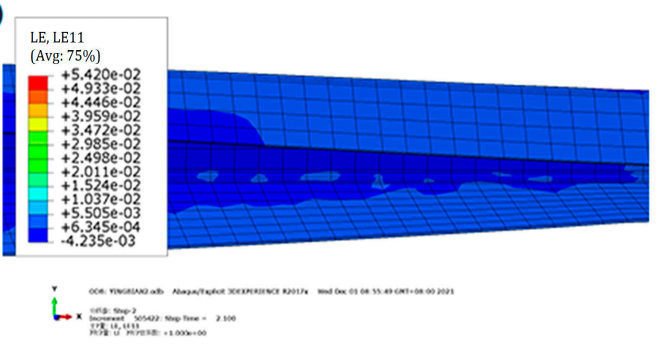

(e)

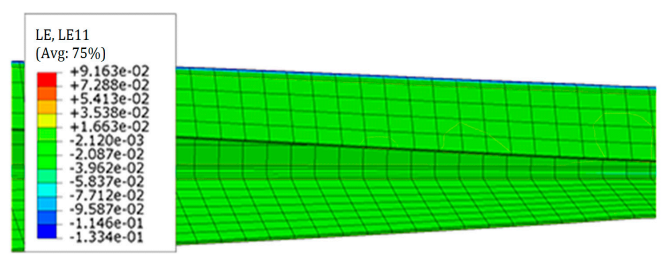

(d)
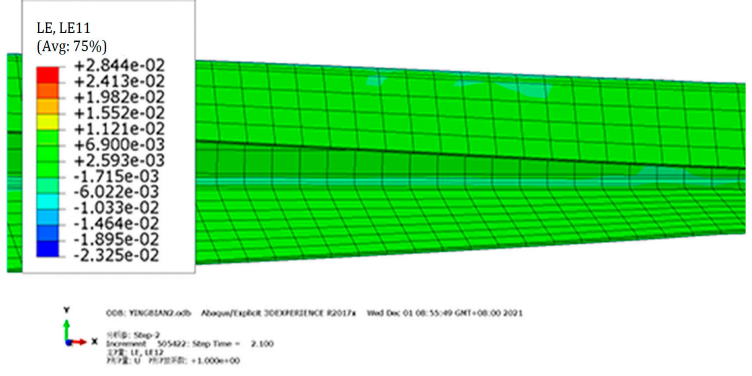

(f)
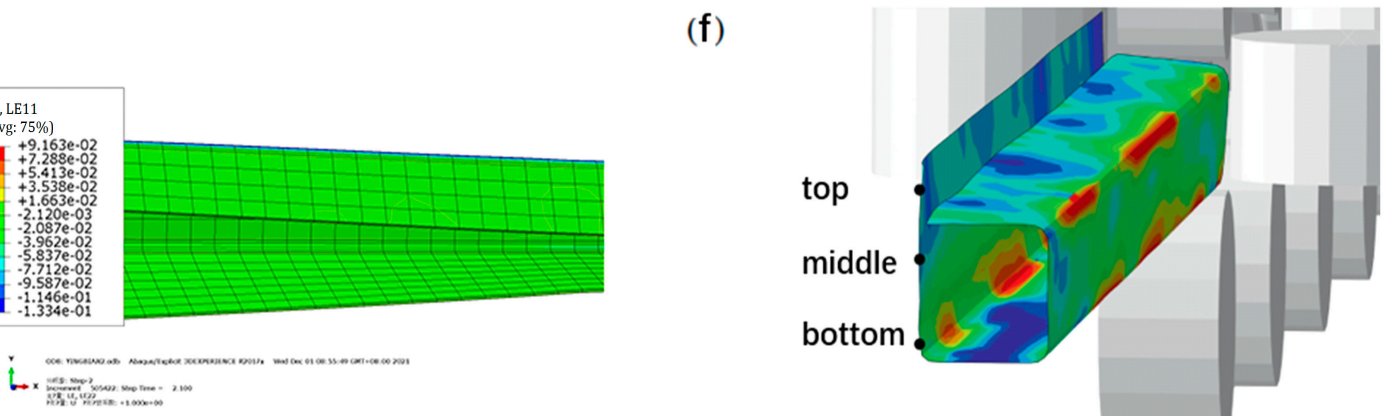

Figure 8. (a) The curve of stress changing with longitudinal distance. (b) The curve of strain changing with longitudinal distance. (c) L11 (strain tensor component). (d) L22 (strain tensor component). (e) L13 (strain tensor component). (f) Identification of the flange parts.

According to the above analysis, it can be concluded from the post-processing of the model that along the roll forming direction, the sheet edge has longitudinal strain, and along the sheet transverse direction, there is shear strain during sheet metal forming. Taking a sheet flange height of $100 \mathrm{~mm}$, a thickness of $3 \mathrm{~mm}$, and a forming speed of $300 \mathrm{~mm} / \mathrm{s}$ as an example, the stress at the top node of the flange and the curve of the node coordinates with the longitudinal distance were analyzed. Figure 9a shows the Mises stress cloud diagram of the " $b$ "-shaped tube. It can be seen that the stress distribution of the entire pipe is uneven, but the overall trend is that the closer the corner is to the pipe, the greater the stress. Figure $9 \mathrm{~b}$ shows the changing curve of the stress and coordinates of the joints at the top of the sheet metal with the longitudinal distance. Figure 9c shows the equivalent strain cloud diagram of the " $b$ "-shaped tube. It can be seen that the strain in the tube mainly occurs at the corners. Figure $9 \mathrm{~d}$ shows the curve of the strain and the coordinate of the node at the top of the sheet as a function of the longitudinal distance. The generation of edge waves at the flange is closely related to stress and strain, and edge wave defects are most likely to occur at the top of the flange. Next, combining different process parameters, the stress and strain of the top node of the flange was analyzed. 
(a)

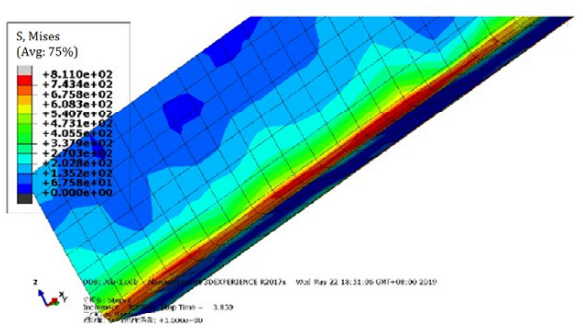

(c)

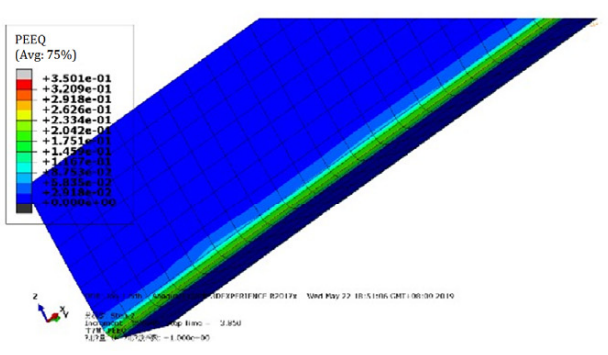

(b)

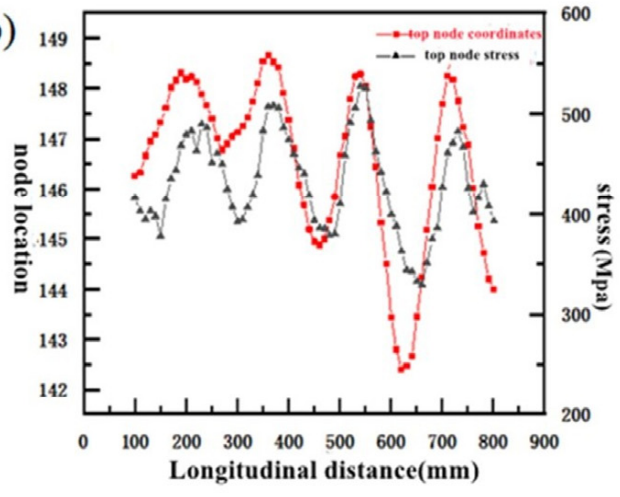

(d)

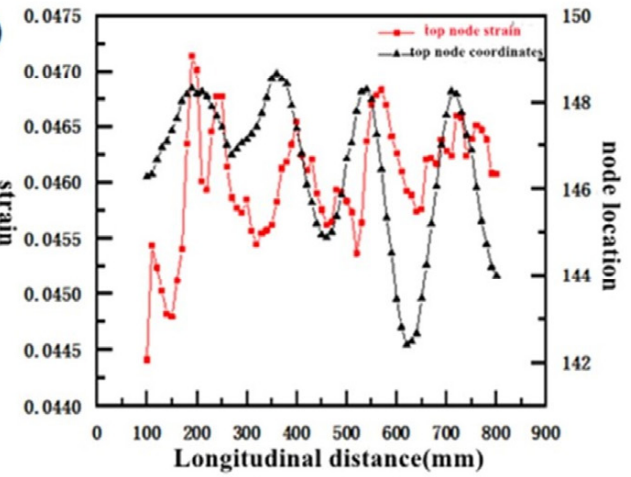

Figure 9. (a) Cloud map of Mises stress for " $b$ "-shaped pipe. (b) The changing curve of the stress and coordinates of the joints at the top of the sheet metal with the longitudinal distance. (c) Cloud map of equivalent strain for " $b$ "-shaped pipe. (d) The changing curve of the strain, the coordinates of the joints at the top of the sheet metal, and the longitudinal distance.

\subsection{Flange Height and Edge Wave}

In order to explore the influence of different flange heights on the edge waves of roll forming parts, the parameters set in the simulation were as follows: the sheet thickness was $3 \mathrm{~mm}$, the forming speed was $300 \mathrm{~mm} / \mathrm{s}$, and the flange heights were selected as $100 \mathrm{~mm}, 120 \mathrm{~mm}$ and $140 \mathrm{~mm}$. Figure 10a,b show the variation curves of equivalent stress and equivalent strain of the top node of the sheet with longitudinal distance under different flange height conditions. Figure 10c shows under the condition of this processing parameter, the variation curve of the sum of wave heights generated.It can be seen from the figure that as the height of the flange increases, the maximum equivalent stress and strain values of the top node increase, and the increase in the height of the flange will have an adverse effect on the forming process, resulting in aggravated edge wave defects at the flange. This is because an increase in the height of the flange will increase the edge tension of the stretching zone, the compression at the edge of the compression zone will also increase, and the increase of the edge compression will directly lead to greater edge wave defects. Therefore, in the actual manufacturing process, we can control the edge wave by reducing the height of the flange on the basis of meeting the size requirements of the part. 

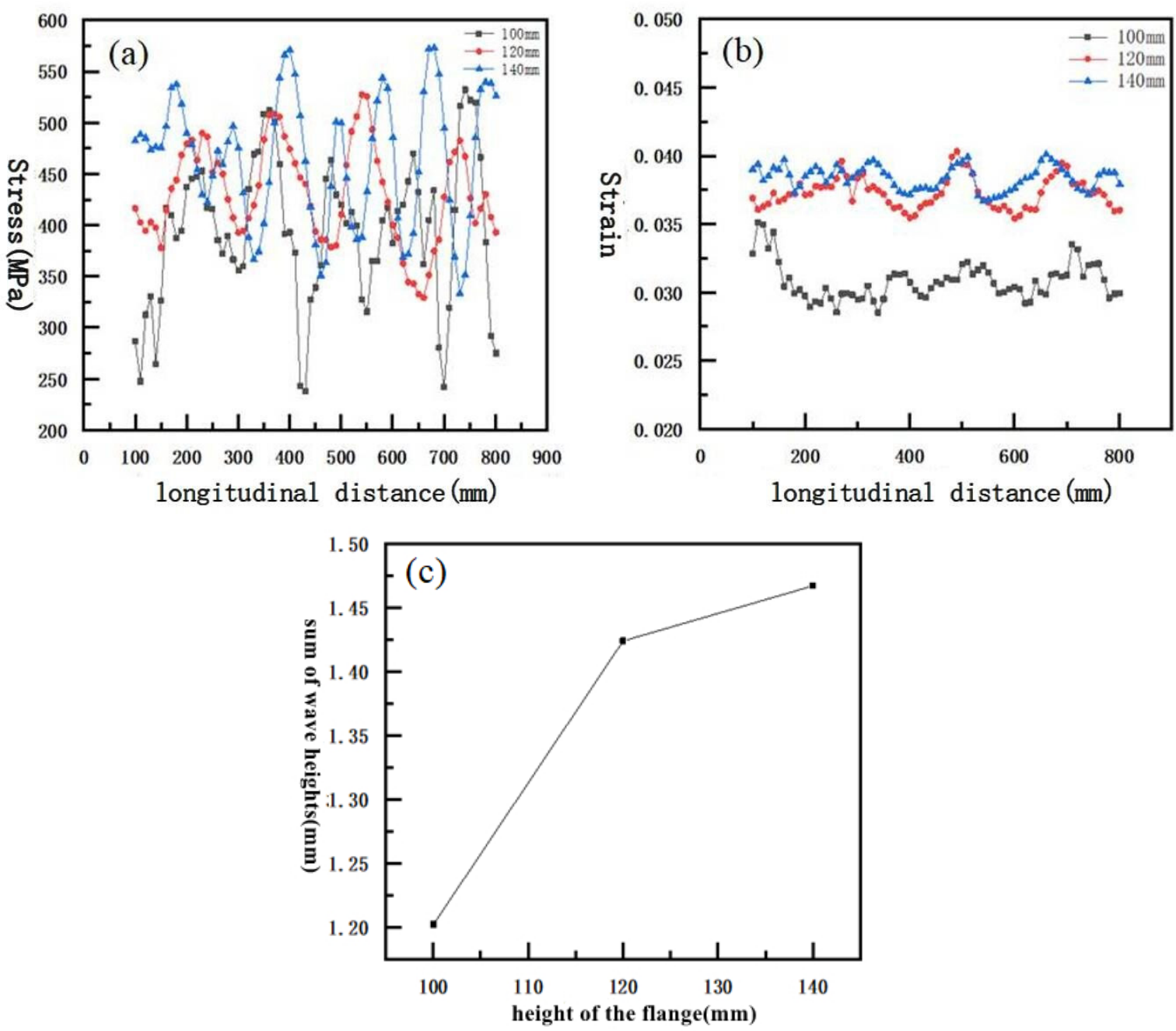

Figure 10. (a) The changing curve of the equivalent stress of the top joint of the sheet metal with the height of the flange. (b) The changing curve of equivalent plastic strain of the top joint of the sheet metal with the height of the flange. (c) The changing curve of the sum of wave heights with the height of the flange.

\subsection{Sheet Thickness and Edge Waves}

In order to explore the influence of different sheet thicknesses on the edge wave of roll forming steel, the parameters set in the simulation were as follows: the flange height was $100 \mathrm{~mm}$, the forming speed was $300 \mathrm{~mm} / \mathrm{s}$, and the sheet thicknesses were $2 \mathrm{~mm}$, $2.5 \mathrm{~mm}$ and $3 \mathrm{~mm}$. Figure 11a,b show the curves of equivalent stress and equivalent strain of the top node of the sheet with the longitudinal distance under different sheet thickness conditions. Figure 11c shows the curve of the change of the sum of wave heights with the thickness of the sheet. It can be seen from the figure that as the thickness of the sheet increases, the required stress during sheet deformation increases, while the sum of wave heights gradually decreases. This is because the increase in sheet thickness increases the forming rigidity of the outer flange, thereby improving its ability to resist edge wrinkles and reducing the occurrence of edge wave defects. Therefore, thicker plates can produce higher-quality wide profiles. Therefore, in actual processing, on the basis of meeting the required thickness of the parts, we can increase the thickness of the plate to reduce the occurrence of edge wave defects. 

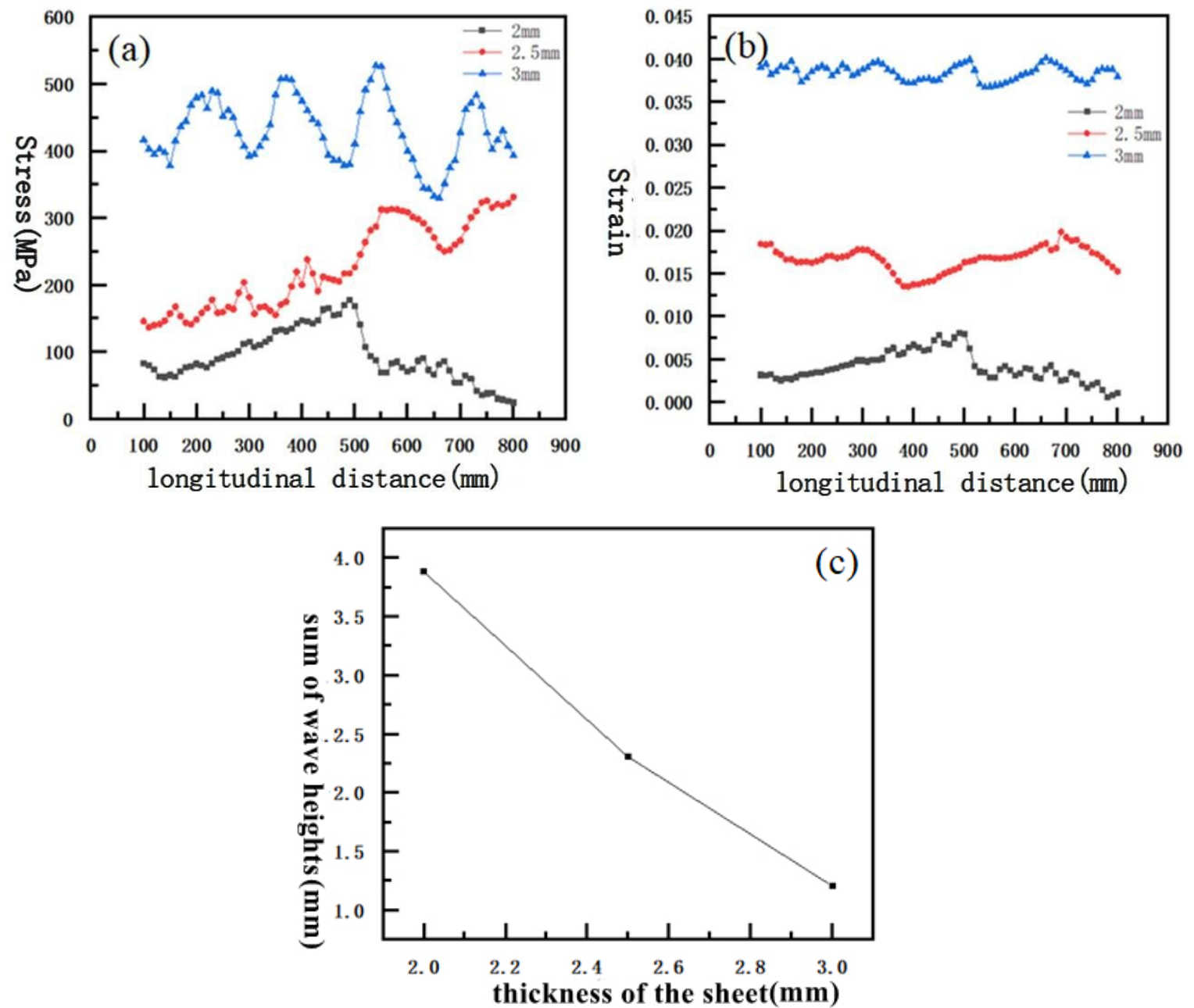

Figure 11. (a) The changing curve of equivalent stress of the top joint with the thickness of the sheet metal. (b) The changing curve of equivalent strain of the top joint with the thickness of the sheet metal. (c) The changing curve of the sum of wave heights with the thickness of the sheet.

\subsection{Forming Speed and Edge Wave}

In order to explore the influence of different forming speeds on the edge wave of rollforming steel, the parameters set in the simulation were as follows: the flange height was $100 \mathrm{~mm}$, the sheet thickness was $3 \mathrm{~mm}$, and the forming speed was $150 \mathrm{~mm} / \mathrm{s}, 200 \mathrm{~mm} / \mathrm{s}$ and $300 \mathrm{~mm} / \mathrm{s}$. Figure 12a,b show the curves of equivalent stress and equivalent strain at the top node of the sheet metal with longitudinal distance under different forming speed conditions. Figure 12c shows, under the condition of this processing parameter, the variation curve of the sum of wave heights generated with the forming speed. It can be seen from the figure that as the forming speed increases, the peak equivalent stress value and the equivalent strain value of the top node of the sheet also increase. This is because for the roll forming process, the sheet metal forming speed set in the macroscopic view can be understood as the strain rate of the sheet metal from the microscopic point of view. According to the plastic forming theory of metal materials, an increase in strain rate will cause the work hardening of the material, and it is the internal strengthening of this material that requires greater deformation force. In addition, the increase in forming speed will also change the friction characteristics between the roll and the sheet metal, and ultimately lead to further aggravation of the edge wave defect of the roll forming steel. Therefore, in the actual manufacturing process, on the basis of meeting the required time of production, we can control the edge wave by reducing the forming speed in order to obtain high-quality roll forming steel. 

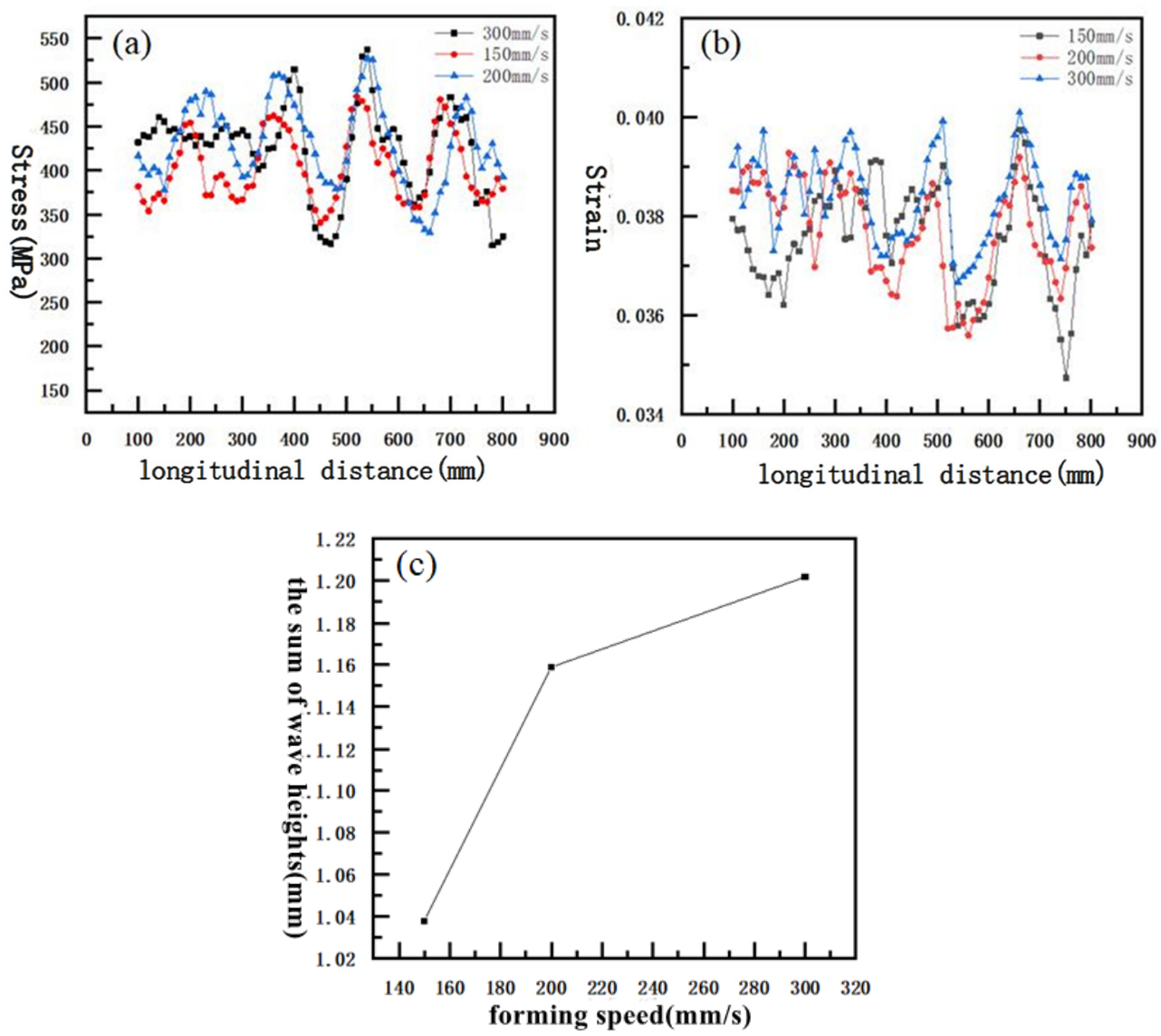

Figure 12. (a) The changing curve of equivalent stress of the top joint with the forming speed of sheet metal. (b) The changing curve of equivalent strain of the top joint with the forming speed of sheet metal. (c) The changing curve of the sum of wave heights with the forming speed.

\subsection{Analysis of Orthogonal Experimental Results of " $b$ "-Shaped Tube Edge Waves}

Through the above exploration, we determined the influence of different process parameters, namely flange height, sheet thickness, and forming speed, on the edge wave of the " $b$ "-shaped cross-section. Then, we further explored the effect of each process parameter on the edge wave through orthogonal experiments. The degree of influence and the results of the orthogonal experiment are shown in Table 3. The larger the longitudinal strain standard deviation $(\Delta \varepsilon)$, the more severe the edge wave, and the larger the range $\Delta R$, which indicates a greater degree of influence on the edge wave defect. From the data in the table, it is shown that every three experiments from the first experiment were used as an experimental group. This intra-group control showed that each process parameter affected the severity of the edge wave, which further verifies the above-mentioned exploration conclusions. Under the conditions of Experiment 21, the longitudinal strain standard deviation $(\Delta \varepsilon)$ of the " $\mathrm{b}$ "-shaped cross-section formed below was the largest, indicating that the edge wave of the " $\mathrm{b}$ "-shaped tube section was the most intense under this process condition. For the longitudinal strain standard of the " $b$ "-shaped cross-section formed under the conditions of Experiment 7, the difference $(\Delta \varepsilon)$ is the smallest, indicating that the edge wave defect of the " $\mathrm{b}$ "-shaped cross-section is the smallest under this process condition. When performing inter-group control, considering the complexity of the data, we selected experiments 1, 2, 3, 7, 16, 25 21, 24, and 27 for calculations. The calculation results are shown in Table 4. It can be seen from the data in the table that the largest difference is the experimental result of changing the thickness of the sheet, the height of the flange is the second largest, and the forming speed is the smallest, indicating that of the process parameters, sheet thickness has the greatest influence on the edge wave of the roll forming product, followed by flange height and then forming speed. 
Table 3. Results of the orthogonal experiments.

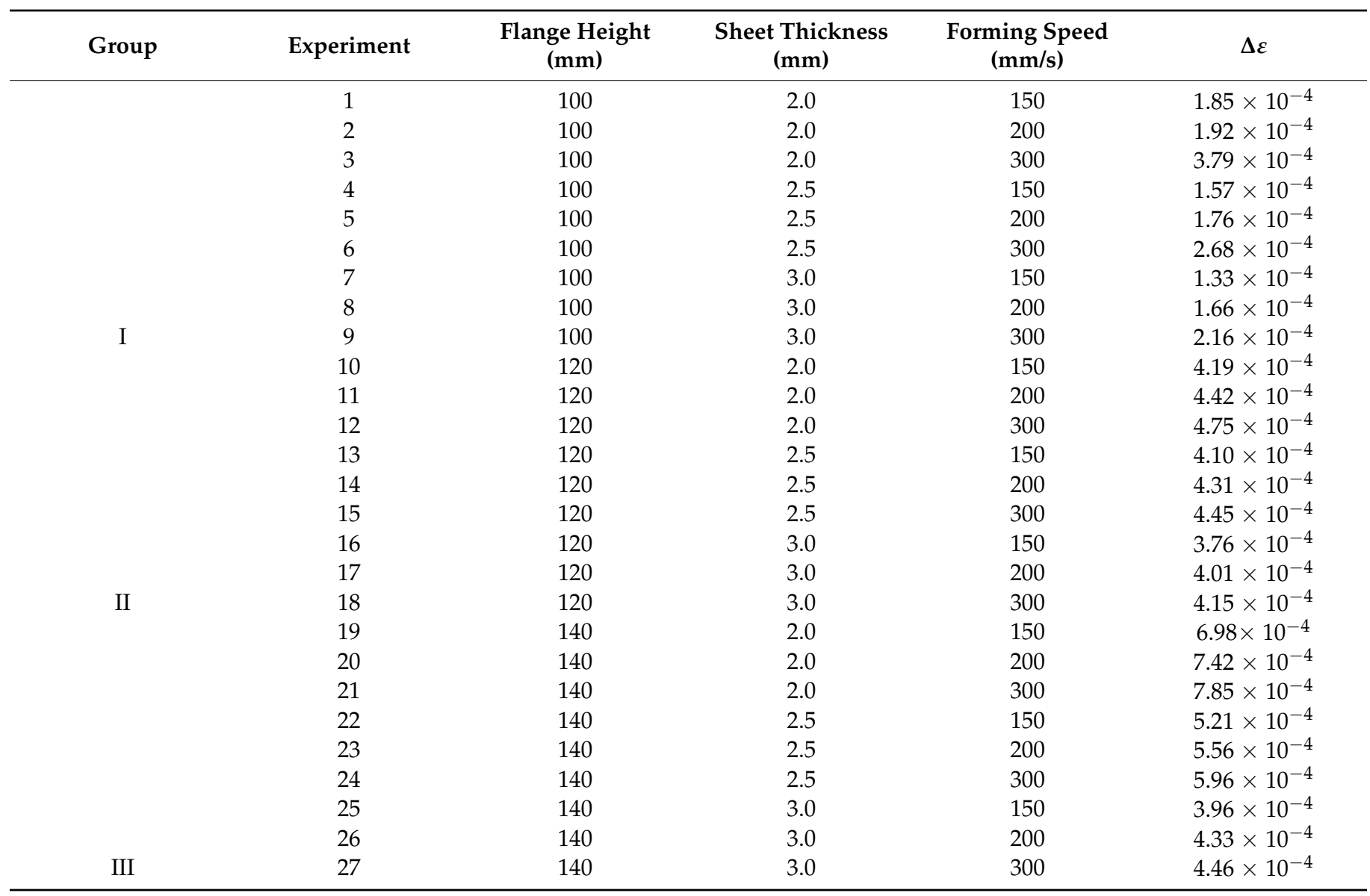

Table 4. Results of the control experiment between parameters.

\begin{tabular}{cccc}
\hline$\Delta \varepsilon$ & Forming Speed & Flange Height & Sheet Thickness \\
\hline I & $1.85 \times 10^{-4}$ & $1.33 \times 10^{-4}$ & $7.85 \times 10^{-4}$ \\
II & $1.92 \times 10^{-4}$ & $3.76 \times 10^{-4}$ & $5.96 \times 10^{-4}$ \\
III & $3.79 \times 10^{-4}$ & $3.96 \times 10^{-4}$ & $4.46 \times 10^{-4}$ \\
$\Delta R$ & $1.94 \times 10^{-4}$ & $2.63 \times 10^{-4}$ & $3.39 \times 10^{-4}$ \\
\hline
\end{tabular}

\section{Conclusions}

This paper used COPRA roll design software to design rolls, ABAQUS finite element modeling and analysis software to simulate the roll forming process, design contrast experiments to explore the influence of different process parameters on the " $b$ "-shaped tube edge wave, and design orthogonal experiments to explore the different degree of influence of process parameters on the edge wave, providing a theoretical basis for the production of "日”-shaped tubes. Our conclusions are as follows:

(1) Compared with the traditional roll forming process, the one-time roll forming process used in this paper greatly improved the utilization rate of materials, product performance, and production efficiency.

(2) Different process parameters (flange height, sheet thickness, and forming speed) will have an impact on the edge wave defects of "日”-shaped cross-section roll-forming products. The influence rules are as follows: the intensity of edge wave increases with an increase of flange height, decreases with an increase of sheet thickness, and increases with an increase of forming speed.

(3) Orthogonal experiment results showed that for high-strength steel sheets with certain material properties, the sheet thickness had the greatest influence of the process 
parameters on the edge wave during the forming process, followed by flange height and then forming speed. The optimal parameter combination selected to minimize edge wave defects was a sheet thickness of $3 \mathrm{~mm}$, a flange height of $100 \mathrm{~mm}$, and a forming speed of $150 \mathrm{~mm} / \mathrm{s}$.

Author Contributions: S.L. and J.L. (Jiandong Li) conducted the numerical modeling and wrote the first draft of manuscript. J.L. (Jicai Liang) provided the concept. S.L., J.L. (Jiandong Li) and C.L. conducted the experiments. C.L. and J.L. (Jicai Liang) edited the draft of manuscript. All authors have read and agreed to the published version of the manuscript.

Funding: This research was funded by Project of Jilin Provincial Scientific and Technological Department, grant number 20190302037GX.

Institutional Review Board Statement: Not applicable.

Informed Consent Statement: Not applicable.

Data Availability Statement: The datasets used or analyzed in the current study are available from the corresponding author on reasonable request.

Acknowledgments: The authors acknowledge all the authors who contributed to this article and the teachers who provided the test analysis.

Conflicts of Interest: The authors declare no conflict of interest.

\section{References}

1. Li, Y.; Han, X.; Liang, J.; Teng, F.; Liang, C. Effect of multi-point roller dies on the forming accuracy of profile in flexible 3D stretch bending technology. Int. J. Adv. Manuf. Technol. 2021, 112, 897-905. [CrossRef]

2. Chen, C.; Liang, J.; Teng, F.; Li, Y.; Liang, C. Research on springback compensation method of 3D flexible stretch bending of multi-point roller dies. Int. J. Adv. Manuf. Technol. 2021, 112, 563-575. [CrossRef]

3. Larranaga, J.; Galdos, L.; Uncilla, L.; Etxaleku, A. Development and validation of a numerical model for strip metal roll forming. Int. J. Mater. Form. 2010, 3, 151-154. [CrossRef]

4. Cao, J.G.; Wang, L.; Liu, J.; Liu, X.L.; Zhao, R.G.; He, Z.L. Finite element simulation of roll forming process based on over-bend de-fect control of shaped tube. J. Cent. South Univ. 2017, 48, 2345-2351.

5. Paralikas, J.; Salonitis, K.; Chryssolouris, G. Optimization of roll forming process parameters-a semi-empirical approach. Int. J. Adv. Manuf. Technol. 2009, 47, 1041-1052. [CrossRef]

6. Paralikas, J.; Salonitis, K.; Chryssolouris, G. Investigation of the effect of roll forming pass design on main redundant defor-mations on profiles from AHSS. Int. J. Adv. Manuf. Technol. 2011, 56, 475-491. [CrossRef]

7. Paralikas, J.; Salonitis, K.; Chryssolouris, G. Investigation of the effects of main roll-forming process parameters on quality for a V-section profile from AHSS. Int. J. Adv. Manuf. Technol. 2009, 44, 223-237. [CrossRef]

8. Abeyrathna, B.; Rolfe, B.; Hodgson, P.; Weiss, M. Local deformation in roll forming. Int. J. Adv. Manuf. Technol. 2016, 88, 2405-2415. [CrossRef]

9. Abeyrathna, B.; Rolfe, B.; Weiss, M. The effect of process and geometric parameters on longitudinal edge strain and product defects in cold roll forming. Int. J. Adv. Manuf. Technol. 2017, 92, 743-754. [CrossRef]

10. McClure, C.K.; Li, H. Roll forming simulation using finite element analysis. Manuf. Rev. 1995, 8, 114-122.

11. Wang, T.; Han, F. Prediction of wrinkling in flexible roll forming based on finite element simulation. Forg. Stamp. Technol. 2013, 38, 67-72.

12. Liang, J.; Chen, C.; Liang, C.; Li, Y.; Chen, G.; Li, X.; Wang, A. One-Time Roll-Forming Technology for High-Strength Steel Profiles with "日" Section. Adv. Mater. Sci. Eng. 2019, 2019, 6505914. [CrossRef]

13. Bui, Q.V.; Ponthot, J.P. Numerical simulation of cold roll-forming processes. J. Mater. Processing Technol. 2008, 202, 275-282. [CrossRef] 